\title{
Update on Inflammation in Chronic Kidney Disease
}

\author{
Oleh M. Akchurin ${ }^{a} \quad$ Frederick Kaskel $^{\mathrm{b}}$ \\ a'Weill Cornell College of Medicine, Department of Pediatrics, New York, N.Y. and ${ }^{b}$ Albert Einstein College of \\ Medicine, Department of Pediatrics, Bronx, N.Y., USA
}

\author{
Key Words \\ Inflammation - Cytokines - Chronic kidney disease . \\ End-stage renal disease - Dialysis · Malnutrition . \\ Protein-energy wasting
}

\begin{abstract}
Background: Despite recent advances in chronic kidney disease (CKD) and end-stage renal disease (ESRD) management, morbidity and mortality in this population remain exceptionally high. Persistent, low-grade inflammation has been recognized as an important component of CKD, playing a unique role in its pathophysiology and being accountable in part for cardiovascular and all-cause mortality, as well as contributing to the development of protein-energy wasting. Summary: The variety of factors contribute to chronic inflammatory status in CKD, including increased production and decreased clearance of pro-inflammatory cytokines, oxidative stress and acidosis, chronic and recurrent infections, including those related to dialysis access, altered metabolism of adipose tissue, and intestinal dysbiosis. Inflammation directly correlates with the glomerular filtration rate (GFR) in CKD and culminates in dialysis patients, where extracorporeal factors, such as impurities in dialysis water, microbiological quality of the dialysate, and bioincompatible factors in the dialysis circuit play an additional role. Genetic and epigenetic influences contributing to inflammatory activation in CKD are currently being intensively investigated. A num-
\end{abstract}

ber of interventions have been proposed to target inflammation in CKD, including lifestyle modifications, pharmacological agents, and optimization of dialysis. Importantly, some of these therapies have been recently tested in randomized controlled trials. Key Messages: Chronic inflammation should be regarded as a common comorbid condition in CKD and especially in dialysis patients. A number of interventions have been proven to be safe and effective in welldesigned clinical studies. This includes such inexpensive approaches as modification of physical activity and dietary supplementation. Further investigations are needed to evaluate the effects of these interventions on hard outcomes, as well as to better understand the role of inflammation in selected CKD populations (e.g., in children).

(c) 2015 S. Karger AG, Basel

\section{Introduction}

Inflammation as an essential part of chronic kidney disease (CKD) has been recognized in the late 1990s, when it was linked to cardiovascular disease, protein-energy wasting, and mortality $[1,2]$. Over the past 15 years, there has been an exponential growth of interest in inflammation in CKD and end-stage renal disease (ESRD), which led to the evolution in our perception of inflammation as not any longer a novel but rather a well-established, if not traditional risk factor of morbidity and mor-

\section{KARGER 125}

(c) 2015 S. Karger AG, Base

$0253-5068 / 15 / 0393-0084 \$ 39.50 / 0$

E-Mail karger@karger.com

www.karger.com/bpu
Oleh M. Akchurin

Division of Nephrology, Weill Cornell Medical College

New York - Presbyterian, Phyllis and David Komansky, Center for Children's Health

505 East 70th Street, 3rd Floor, Box 176, New York, NY 10021 (USA)

E-Mail oma9005@med.cornell.edu 
tality in CKD. In this brief review, we summarize the recent advances in the field of uremic inflammation and its potential clinical implications. Review criteria: we searched both PubMed and Google Scholar databases for all pertinent original papers, meta-analyses and systematic reviews published in English since 1999, with a focus on the more recent publications. References mentioned in the identified publications were searched for further materials.

\section{Outcomes of Inflammation in CKD}

An inverse correlation between GFR and inflammation has now been clearly proven. In the Chronic Renal Insufficiency Cohort (CRIC) study, biomarkers of inflammation (IL-1 $\beta$, IL-1 receptor antagonist, IL-6, TNF- $\alpha$, $\mathrm{CRP}$, and fibrinogen) were inversely associated with the measures of kidney function and positively with albuminuria [3]. Inflammation is present not only in adult, but also in pediatric patients with CKD/ESRD [4]. Interestingly, the erythrocyte sedimentation rate (ESR) in adolescents has been shown to be predictive of ESRD in middle-aged men [5].

Different biomarkers of inflammation appear to have a different predictive value in CKD/ESRD. In a large multi-central international database of hemodialysis (HD) patients, CRP predicted mortality with a precision, comparable with that of albumin and exceeding ferritin and white blood cell count [6]. It appears, however, that IL-6 predicts all-cause and cardiovascular mortality better than CRP and other cytokines, such as TNF-alpha, IL1beta and IL-18 [7, 8].

Specification of the role that individual cytokines play in CKD and ESRD is ongoing. Thus, IL-2 was elevated in HD patients with uremic pruritus, when compared to age-gender matched HD controls without pruritus [9]. Based on the animal data, it was suggested that obesityrelated CKD may be associated with spleen-derived IL-10 [10]. TNF-like weak inducer of apoptosis (TWEAK) was recently found to stimulate the expression of inflammatory cytokines locally in kidney cells and to down-regulate the expression of Klotho in vitro and in vivo [11]. Soluble TWEAK levels were independently associated with coronary artery disease severity in patients with stage 2-3 CKD [12].

Availability of multiplex technology allowed investigators to move from the analysis of individual cytokines to assessing cytokine panels. Cohen et al. in a cohort of HD patients described a pro-inflammatory pattern of high
IL-1, IL-6, and TNF- $\alpha$ in combination with low anti-inflammatory parameters, including IL-2, IL-4, IL-5, IL-12, $\mathrm{CH} 50$ and T-cell number, and demonstrated that patients with high pro-inflammatory cytokines had decreased survival compared to patients without a characteristic cytokine pattern [13].

Recently, significant attention has been devoted to the role of adipokines in $\mathrm{CKD}$, such as pro-inflammatory leptin, apelin, omentin, visfatin, resistin and anti-inflammatory adiponectin $[14,15]$. Analysis of the data from the National Health and Nutrition Examination Survey (NHANES) demonstrated that CKD is associated with higher leptin levels [16]. Adiponectin levels measured in ESRD patients were also significantly higher than in controls with normal kidney function [17]. In stages 2-5 $\mathrm{CKD}$, leptin was associated with metabolic syndrome score and PTH [18]. In non-diabetic peritoneal dialysis patients, Leptin/Adiponectin ratio was found to be an independent predictor of mortality, superior to individual adipokines [19].

Persistent inflammation in CKD is not only related to cardiovascular outcomes, including early atherosclerosis, but is also one of the key players in the development of malnutrition/protein-energy wasting (PEW), which led to the description of the malnutrition-inflammation-cachexia syndrome (MICS) in CKD/ESRD [20]. Hypoalbuminemia is strongly associated with mortality in dialysis patients [21] but it is now clear that this association is partly explained by inflammation, and not only by malnutrition [22].

There are few potential mechanisms by which inflammation can cause PEW [23]. Pro-inflammatory cytokines may directly cause anorexia via influence on the brain. In addition, inflammatory markers, particularly IL-6, may be associated with depression in CKD and ESRD, which by itself is a predictor of morbidity and mortality [24] and can cause decreased nutrient intake. However, inflammation may not only cause true malnutrition, but can also increase resting energy expenditure. The immune system itself is the third leading energy consumer in the body after the brain and muscles. Furthermore, inflammation suppresses anabolic hormones, such as growth hormone, IGF-1 and testosterone [25]. Interestingly, inflammation is known to suppress linear growth in children with various inflammatory disorders, and growth failure is the characteristic feature of pediatric CKD [26]. However, the possible influence of inflammation on growth in children with CKD has not been sufficiently investigated.

Another series of consequences of inflammation in $\mathrm{CKD}$ is related to its role in the pathophysiology of ane- 


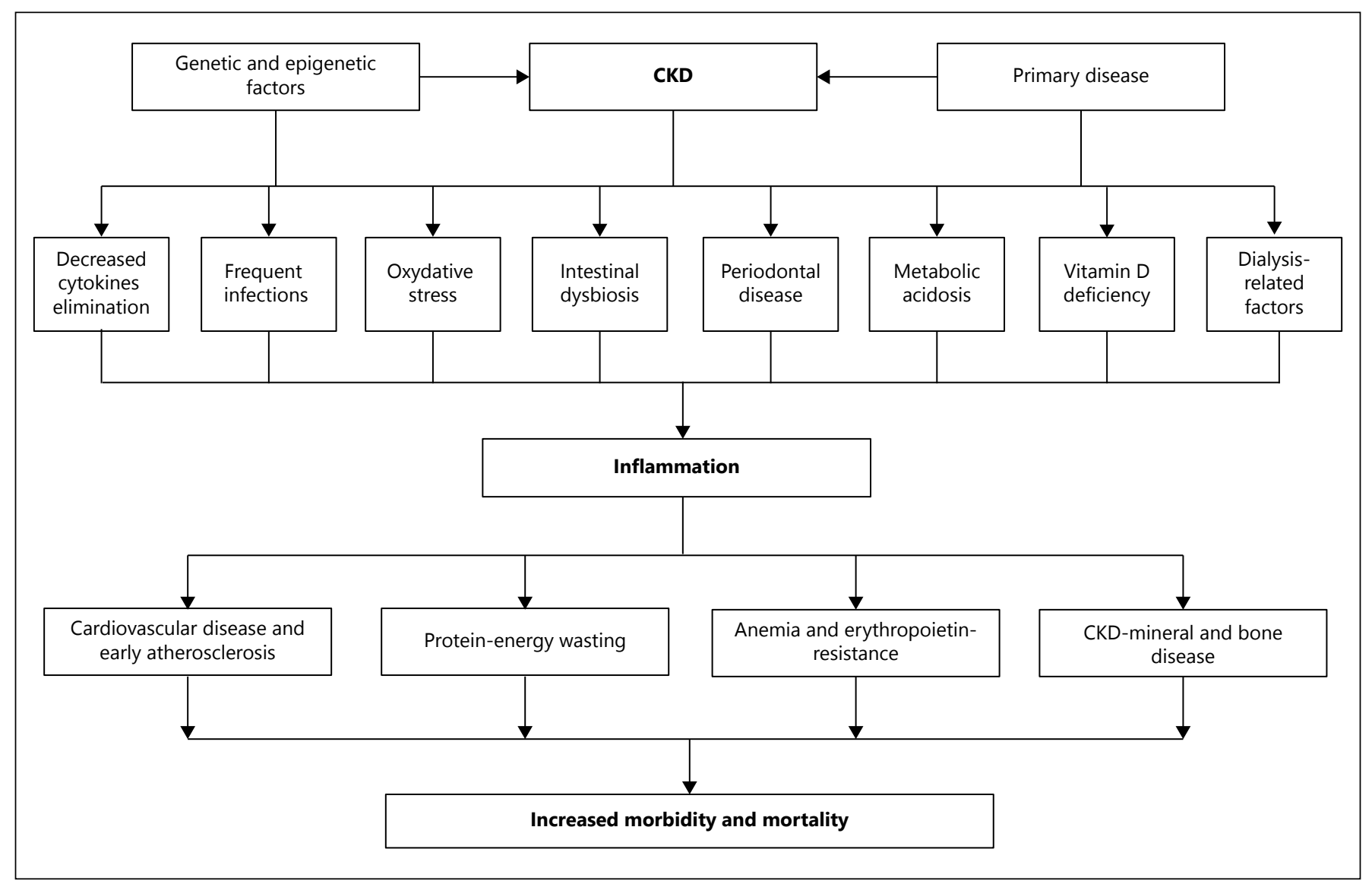

Fig. 1. Causes and consequences of inflammation in chronic kidney disease.

mia and mineral and bone disorder (CKD-MBD), including growth retardation in children with CKD (fig. 1). TNF-alpha, one of the most powerful inducers of the receptor activator of NF- $\kappa B$ ligand (RANKL) - a key trigger of osteoclast activation and bone resorption, may be associated with incident fractures in dialysis patients [27]. In the CRIC study, higher FGF23 levels were independently associated with higher levels of IL-6, CRP, TNFalpha, and fibrinogen [28]. IL-1 and IL-6 were shown to suppress PTH secretion and it was suggested that in a subset of dialysis patients, low PTH levels could reflect the malnutrition-inflammation-cachexia syndrome rather than the low bone turnover disease [29]. In pediatric dialysis patients, low $1,25(\mathrm{OH})_{2}$ vitamin $\mathrm{D}$ levels were associated with higher CRP [30].

Inflammation in CKD is one of the important factors contributing to anemia and erythropoietin (Epo) resistance [31]. The effects of inflammation on Epo resistance in CKD are multiple, and involve decreased Epo production [32], decreased stimulatory activity of Epo on eryth- ropoiesis [33], and increased production of hepcidin, which disrupts iron metabolism [34].

The pathophysiology of inflammation may not be the same in CKD patients of different racial, ethnic, and genetic backgrounds. In a large cohort of dialysis patients, Crews et al. demonstrated that known racial differences in survival among dialysis patients are not present at low levels of inflammation but are prominent at higher levels; this indicated that inflammation may explain, in part, the racial paradox of ESRD survival [35]. Recent findings from the CRIC study demonstrated that Caucasians have a stronger association of adiposity with markers of inflammation compared to African Americans [36]. In the large Japan Multi-Institutional Collaborative Cohort (JMICC) study, the functional promoter polymorphisms IL-4 T-33C (rs2070874) and IL-6 C-572G (rs1800796), which are the only SNPs that affect the IL-4 and IL-6 levels in Japanese subjects, were associated with kidney function and CKD prevalence [37]. It was demonstrated that certain IL-10 genotypes may protect dialysis patients 
from cardiovascular events [38]. The complex nature of genetic influences in CKD and inflammation can be illustrated by the interesting finding of a study, in which genetic predisposition to produce low levels of IL-10 was found to be associated with depressive symptoms in patients with ESRD [39]. All these data suggest that significant genetic and epigenetic effects may modify inflammatory activity in CKD.

\section{Etiology of Inflammation in CKD}

Multiple factors can contribute to immune dysregulation and inflammatory activation in CKD (figure 1). Some of them may be related to the primary disease rather than to uremia per se. Other modifiers originate from the genetic background, as well as from the diet, life-style and environment, representing epigenetic influences. Decreased renal clearance clearly accounts for higher levels of circulating cytokines, although increased production has also been described [40]. Uremic milieu produces oxidative stress [41] and carbonyl stress [42] that are highly pro-inflammatory. Interestingly, oxidative stress markers were used to predict response to iron treatment in CKD [43]. Metabolic acidosis is another cause of inflammation in CKD [44].

$\mathrm{CKD}$ and especially dialysis patients are prone to frequent infectious and thrombotic events, which create additional inflammatory stimulations. This includes catheter-related bloodstream infections, access site infections, thrombosed IV fistulas and grafts, and episodes of peritonitis in PD patients [45]. Oral disease is common in patients with CKD [46], and chronic periodontal inflammation is associated with systemic elevation of inflammatory biomarkers in HD patients and adversely affects patients' survival $[47,48]$.

It was suggested that uremic toxins may contribute to intestinal dysbiosis in CKD and lead to an increased translocation of gut bacteria and bacterial components into the circulation, which can in turn activate systemic inflammation [49-51]. A recent cross-sectional study in stage 3-4 CKD demonstrated that indoxyl sulfate and pcresyl sulfate (nephro- and cardiovascular toxins, produced solely by the gut microbiota) were associated with elevated levels of inflammatory biomarkers as well as with increased arterial stiffness [52].

The role of vitamin $\mathrm{D}$ as a regulator of the immune system is now well established. In addition to the inability to form $1,25(\mathrm{OH})_{2}$ vitamin $\mathrm{D}$, many patients with $\mathrm{CKD}$ also loose the capacity to maintain normal serum
$25(\mathrm{OH})$ vitamin D levels [53]. The immune dysfunction associated with vitamin $\mathrm{D}$ deficiency in patients with CKD and ESRD has been proposed as one of the causes of the misdirected inflammatory response seen in this population [54].

Inflammatory cytokines in CKD are produced not only by lymphocytes, but also by various tissues, such as adipose tissue, which becomes dysfunctional in CKD [14]. Thus, visceral adipose tissue in ESRD has high mRNA expression of pro-inflammatory cytokines, such as TNF- $\alpha, \mathrm{CD} 68$, adiponectin receptor- 1 , and monocyte chemoattractant protein-1 [55]. In stage 3-5 CKD, visceral fat volume correlates with circulating IL-6 [56]. Interestingly, elevated leptin levels in pediatric CKD may not be related to decreased clearance but could rather reflect true overproduction, as in CKiD cohort leptin levels did not correlate with GFR [57]. While adiponectin is elevated in CKD and results in upregulation of Adiponectin receptor-1, its expected anti-inflammatory effects may be blunted by the development of adiponectin resistance at the post-receptor level [58].

It was shown that hemodialysis treatment acutely upregulate transcription of pro-inflammatory cytokines [59]. A number of extracorporeal factors have been implicated into inflammatory activation in dialysis patients, including impurities in dialysis water, microbiological quality of the dialysate, and bioincompatible factors in the extracorporeal dialysis circuit $[60,61]$.

\section{Correction of Inflammation in CKD}

A variety of interventions that have been proposed to target inflammation in CKD can be divided into three broad categories: lifestyle modifications, pharmacological interventions, and optimization of dialysis [62].

In-center meals or oral supplements and exercise programs provided during dialysis therapy or at home are feasible and inexpensive interventions that could improve survival and quality of life in patients with ESRD $[63,64]$. The individual response to these interventions, however, may significantly depend on the baseline inflammatory activity [65].

It appears that not only the total nutrient/energy intake but also the representation of specific dietary components may influence inflammation in CKD. Among the various dietary supplementations suggested to alter inflammation in CKD were omega-3 fatty acids/fish oil, catechins/decaffeinated green tea extract $[66,67]$, pomegranate juice, soy isoflavones [68], fibers, and probiotics. 
Thus, recent study found that fish oil altered the gene expression profile of adipose tissue toward an anti-inflammatory status, particularly by up-regulating adipokine genes in non-dialysis patients with CKD [69]. In a randomized placebo-controlled trial supplementation of HD patients with gamma-tocopherol and docosahexaenoic acid decreased IL-6 [70]. Recent meta-analysis concluded that marine-derived $n-3$ polyunsaturated fatty acids lower CRP, IL-6, and TNFa [71].

In a randomized placebo-controlled trial, it was found that pomegranate juice intake decreased IL- 6 and TNFalpha, oxidative stress, and incidence of infections in $\mathrm{HD}$ patients [72]. Based on another randomized study, pomegranate juice intake attenuated the increase in oxidative stress induced by intravenous iron during HD [73]. Randomized crossover clinical trial demonstrated that soy milk consumption resulted in a significant reduction in D-dimer level but had no significant effects on IL-6, TNFalpha, and CRP in patients with diabetic nephropathy [74].

Based on the analysis of a large sample from the NHANES III, a high dietary fiber intake was associated with decreased CRP and all-cause mortality in patients with chronic kidney disease [75]. A strong interest to probiotic use in CKD/ESRD emerged in recent years, and various outcomes have been investigated [76, 77]. An anti-inflammatory effect of probiotics currently has been demonstrated in animal models [78], but sufficiently powered clinical studies are still lacking [51].

Given the known immune-modulating properties of vitamin $\mathrm{D}$, it seems logical to hypothesize that vitamin $\mathrm{D}$ supplementation would improve the inflammatory status in vitamin-D-deficient CKD patients. However, the results of available clinical studies remain controversial. Stubbs et al. reported that cholecalciferol supplementation altered calcitriol-responsive monocyte proteins and decreased inflammatory cytokines in 7 HD patients [79]. Conversely, recent randomized crossover trial did not find differences in IL-6, TNF- $\alpha$ and CRP following vitamin $\mathrm{D}$ analogs supplementation in chronic HD patients [80].

Growth hormone is currently considered an anabolic agent in adult HD patient with protein-energy wasting [64]. Structurally, growth hormone belongs to cytokine family, and its ability to modulate inflammatory response has been an area of active investigation [81]. In a large multicenter randomized controlled trial, growth hormone supplementation in maintenance HD patients led to a significant decrease in CRP and homocysteine, and increase in serum HDL cholesterol and transferrin [64].
It remains unknown whether growth hormone therapy in children with CKD-related growth failure provides any anti-inflammatory benefit.

Physical activity was shown to decrease inflammatory activity in both healthy subjects and in patients with various chronic inflammatory conditions, including CKD [82]. In patients with pre-dialysis CKD, six months of regular walking exercise ( $30 \mathrm{~min} /$ day for 5 days/week) exerted anti-inflammatory effects (reduction in the ratio of plasma IL-6 to IL-10 levels) and a down-regulation of Tlymphocyte and monocyte activation [83]. The benefit of exercise in CKD population obviously goes far beyond its anti-inflammatory effects, as it can also improve physical functioning and impacts positively on the mediators of co-morbid diseases and upstream factors associated with progression of renal disease [84].

Pharmacologic interventions aimed to reduce inflammation in CKD include use of known CKD therapies for the broader or non-traditional indications (e.g., growth hormone and vitamin $\mathrm{D}$, as discussed earlier), novel agents to control pathophysiologic mechanisms triggering inflammatory response (i.e., antioxidants), and specific anti-cytokine therapies.

Some traditional CKD therapies have been shown to have anti-inflammatory properties when used in other conditions as well as in animal models. A number of recent studies were aimed at identifying the potential effects of these drugs on inflammation in CKD. Thus, a metaanalysis demonstrated that statins can improve chronic inflammatory status in dialysis patients [85]. Angiotensin II blockade in stages 3 and 4 CKD with olmesartan for 16 weeks resulted in a significant reduction of CRP and fibrinogen but no differences in adipokine levels [86]. Much debate and controversy have been recently in the literature around the various effects of sodium restriction in CKD [87]. A randomized trial conducted by Campbell et al. found no effect of low-sodium diet on pro- or antiinflammatory adipokynes in CKD patients [88]. This and other data suggest that pleiotropic pro- or anti-inflammatory properties of the traditional CKD medications should be taken into account by the clinicians when prescribing them to individual patients.

Correction of oxidative stress is another line of antiinflammatory interventions in CKD that has been recently a focus of an extensive investigation. Gamma-tocopherol, docosaheaxoenoic acid, $\mathrm{N}$-acetylcysteine, bardoxolone methyl, and vitamin-E-coated dialysis membranes are some of the proposed therapies [23]. In a randomized, double-blinded, placebo-controlled trial, gamma-tocopherol and docosahexaenoic acid administration sig-
88

Blood Purif 2015;39:84-92 DOI: $10.1159 / 000368940$
Akchurin/Kaskel 
nificantly decreased IL-6, WBC count, and neutrophil fraction of WBCs in HD patients, but did not change $\mathrm{CRP}, \mathrm{F}_{2}$ isoprostanes, or protein carbonyl content [70]. A recent meta-analysis concluded that vitamin E-coated dialyzer can reduce the oxidative stress and inflammation status without affecting the dialysis adequacy [89].

Targeting specific cytokines in CKD is an attractive goal as the specific anti-IL-1, anti-IL-6, and anti-TNFalpha therapies have been already developed and tested in other conditions; however, trials in patients with CKD remain limited. Administration of IL-1 receptor antagonist in HD patients significantly improved CRP and IL-6 and showed a trend toward the increase of serum albumin, pre-albumin, and lean body mass [90]; it also improved adiponectin levels [91].

For ESRD patients, two main approaches to decrease inflammatory load related to the dialysis procedure were proposed: elimination of factors triggering inflammation and direct removal of inflammatory mediators [60]. Interventions that were tested include the use of biocompatible membranes, stringent purity standards for HD water, ultrapure dialysate, increased dialysis frequency, and hemodiafiltration.

Recent meta-analysis demonstrated that the use of ultrapure dialysate in HD patients results in a decrease in markers of inflammation and oxidative stress, an increase in serum albumin and hemoglobin and a decrease in erythropoietin requirement [92]. Short daily dialysis, as compared with conventional HD, lowered CRP and improved erythropoietin sensitivity [93]. Recent metaanalysis showed the beneficial effect of frequent or extended hemodialysis on cardiovascular outcomes [94]. Hemodiafiltration may decrease inflammatory activity via additional clearance of middle molecules by convection. In the analysis of a large dataset from the randomized controlled Convective Transport Study (CONTRAST), den Hoedt et al. found that online hemodiafiltration indeed reduced systemic inflammation (CRP and IL-6) compared with low-flux HD [95]. The 'RISchio CArdiovascolare nei pazienti afferenti all Area Vasta In Dialisi' (RISCAVID) study demonstrated that hemodiafiltration was associated with an improved cumulative survival independent of the dialysis dose [96].

In summary, persistent low-grade inflammation has been recently recognized as an essential component of $\mathrm{CKD}$, playing a unique role in its pathophysiology and being accountable in part for cardiovascular and all-cause mortality, as well as development of protein-energy wasting and other comorbid conditions. A variety of factors contribute to chronic inflammatory status in CKD, including increased production and decreased clearance of pro-inflammatory cytokines, oxidative stress and acidosis, chronic and recurrent infections, altered metabolism of the adipose tissue, and intestinal dysbiosis. Extracorporeal factors, such as impurities in dialysis water, microbiological quality of the dialysate, and bioincompatible factors in the dialysis circuit play an additional role. Genetic and epigenetic factors contributing to inflammatory activation in CKD are currently being intensively investigated. A number of interventions have been proposed to target inflammation in CKD, including lifestyle modifications, pharmacological interventions, and optimization of dialysis. Importantly, some of these therapies have been recently tested in randomized controlled trials. Further investigations are needed to evaluate the effects of these interventions on hard outcomes, as well as to better understand the role of inflammation in selected CKD populations, particularly in children.

\section{References}

$>1$ Stenvinkel P, Heimburger O, Paultre F, Diczfalusy U, Wang T, Berglund L, Jogestrand T: Strong association between malnutrition, inflammation, and atherosclerosis in chronic renal failure. Kidney Int 1999;55:1899-1911.

$>2$ Zimmermann J, Herrlinger S, Pruy A, Metzger T, Wanner C: Inflammation enhances cardiovascular risk and mortality in hemodialysis patients. Kidney Int 1999;55:648-658.

$>3$ Gupta J, Mitra N, Kanetsky PA, Devaney J, Wing MR, Reilly M, Shah VO, Balakrishnan VS, Guzman NJ, Girndt M, Periera BG, Feldman HI, Kusek JW, Joffe MM, Raj DS: Association between albuminuria, kidney function, and inflammatory biomarker profile in CKD in CRIC. Clin J Am Soc Nephrol 2012;7:1938-1946.
4 Goldstein SL, Leung JC, Silverstein DM: Proand anti-inflammatory cytokines in chronic pediatric dialysis patients: effect of aspirin. Clin J Am Soc Nephrol 2006;1:979-986.

$\checkmark 5$ Sundin PO, Udumyan R, Sjostrom P, Montgomery S: Predictors in adolescence of ESRD in middle-aged men. Am J Kidney Dis 2014; 64:723-729.

6 Bazeley J, Bieber B, Li Y, Morgenstern H, de Sequera P, Combe C, Yamamoto H, Gallagher M, Port FK, Robinson BM: C-reactive protein and prediction of 1-year mortality in prevalent hemodialysis patients. Clin J Am Soc Nephrol 2011;6:2452-2461.

7 Honda H, Qureshi AR, Heimburger O, Barany $\mathrm{P}$, Wang $\mathrm{K}$, Pecoits-Filho $\mathrm{R}$, Stenvinkel
P, Lindholm B: Serum albumin, C-reactive protein, interleukin 6 , and fetuin a as predictors of malnutrition, cardiovascular disease, and mortality in patients with ESRD. Am J Kidney Dis 2006; 47:139-148.

$>8$ Tripepi G, Mallamaci F, Zoccali C: Inflammation markers, adhesion molecules, and allcause and cardiovascular mortality in patients with ESRD: searching for the best risk marker by multivariate modeling. J Am Soc Nephrol 2005; 16:S83-S88.

$>9$ Fallahzadeh MK, Roozbeh J, Geramizadeh B, Namazi MR: Interleukin-2 serum levels are elevated in patients with uremic pruritus: a novel finding with practical implications. Nephrol Dial Transplant 2011;26:3338-3344. 
10 Gotoh K, Inoue M, Masaki T, Chiba S, Shiraishi K, Shimasaki T, Matsuoka K, Ando H, Fujiwara K, Fukunaga N, Aoki K, Nawata T, Katsuragi I, Kakuma T, Seike M, Yoshimatsu H: Obesity-related chronic kidney disease is associated with spleen-derived IL-10. Nephrol Dial Transplant 2013;28:1120-1130.

-11 Sanz AB, Izquierdo MC, Sanchez-Nino MD, Ucero AC, Egido J, Ruiz-Ortega M, Ramos AM, Putterman C, Ortiz A: TWEAK and the progression of renal disease: clinical translation. Nephrol Dial Transplant 2014;29(suppl 1):i54-i62.

-12 Azak A, Akdogan MF, Denizli N, Huddam B, Kocak G, Gucun M, Tatlisu MA, Demirci R, Yilmaz B, Dikec M, Bakirtas M, Akdag I, Duranay M: Soluble TWEAK levels are independently associated with coronary artery disease severity in patients with stage 2-3 kidney disease. Int Urol Nephrol 2014;46: 411-415.

13 Cohen SD, Phillips TM, Khetpal P, Kimmel PL: Cytokine patterns and survival in haemodialysis patients. Nephrol Dial Transplant 2010;25:1239-1243.

14 Iglesias P, Diez JJ: Adipose tissue in renal disease: clinical significance and prognostic implications. Nephrol Dial Transplant 2010;25: 2066-2077.

15 Miyamoto S, Sharma K: Adipokines protecting CKD. Nephrol Dial Transplant 2013; 28(suppl 4):iv15-iv22.

16 Shankar A, Syamala S, Xiao J, Muntner P: Relationship between plasma leptin level and chronic kidney disease. Int J Nephrol 2012; 2012:269532.

-17 Adamczak M, Chudek J, Wiecek A: Adiponectin in patients with chronic kidney disease. Semin Dial 2009;22:391-395.

$\checkmark 18$ de Oliveira RB, Liabeuf S, Okazaki H, Lenglet A, Desjardins L, Lemke HD, Vanholder R, Choukroun G, Massy ZA: The clinical impact of plasma leptin levels in a cohort of chronic kidney disease patients. Clin Kidney J 2013;6: 63-70.

-19 Park JT, Yoo TH, Kim JK, Oh HJ, Kim SJ, Yoo DE, Lee MJ, Shin DH, Han SH, Han DS, Kang SW: Leptin/adiponectin ratio is an independent predictor of mortality in nondiabetic peritoneal dialysis patients. Perit Dial Int 2013;33:67-74.

20 Kalantar-Zadeh K: Recent advances in understanding the malnutrition-inflammation-cachexia syndrome in chronic kidney disease patients: what is next? Semin Dial 2005;18: 365-369.

-21 Kalantar-Zadeh K, Kilpatrick RD, Kuwae N, McAllister CJ, Alcorn H Jr, Kopple JD, Greenland S: Revisiting mortality predictability of serum albumin in the dialysis population: time dependency, longitudinal changes and population-attributable fraction. Nephrol Dial Transplant 2005;20:1880-1888.

$\checkmark 22$ de Mutsert R, Grootendorst DC, Indemans F, Boeschoten EW, Krediet RT, Dekker FW: Association between serum albumin and mortality in dialysis patients is partly explained by inflammation, and not by malnutrition. J Ren Nutr 2009;19:127-135.

23 Stenvinkel P: Can treating persistent inflammation limit protein energy wasting? Semin Dial 2013;26:16-19.

24 Taraz M, Taraz S, Dashti-Khavidaki S: Association between depression and inflammatory/anti-inflammatory cytokines in chronic kidney disease and end-stage renal disease patients: a review of literature. Hemodial Int 2014, DOI: 10.1111/hdi.12200, Epub ahead of print.

25 Meuwese CL, Carrero JJ, Stenvinkel P: Recent insights in inflammation-associated wasting in patients with chronic kidney disease. Contrib Nephrol 2011;171:120-126.

26 Mahesh S, Kaskel F: Growth hormone axis in chronic kidney disease. Pediatr Nephrol 2008; 23:41-48.

27 Panuccio V, Enia G, Tripepi R, Aliotta R, Mallamaci F, Tripepi G, Zoccali C: Pro-inflammatory cytokines and bone fractures in CKD patients. An exploratory single centre study. BMC Nephrol 2012;13:134.

28 Munoz Mendoza J, Isakova T, Ricardo AC, Xie H, Navaneethan SD, Anderson AH, Bazzano LA, Xie D, Kretzler M, Nessel L, Hamm LL, Negrea L, Leonard MB, Raj D, Wolf M: Fibroblast growth factor 23 and Inflammation in CKD. Clin J Am Soc Nephrol 2012;7: 1155-1162.

29 Feroze U, Molnar MZ, Dukkipati R, Kovesdy $\mathrm{CP}$, Kalantar-Zadeh K: Insights into nutritional and inflammatory aspects of low parathyroid hormone in dialysis patients. J Ren Nutr 2011;21:100-104.

30 Shroff R, Egerton M, Bridel M, Shah V, Donald AE, Cole TJ, Hiorns MP, Deanfield JE, Rees L: A bimodal association of vitamin D levels and vascular disease in children on dialysis. J Am Soc Nephrol 2008;19:1239-1246.

31 Kovesdy CP: How can erythropoeitin-stimulating agent use be reduced in chronic dialysis patients?: can reduction of inflammation improve ESA dose response? Semin Dial 2013; 26:540-542.

32 Jelkmann W: Proinflammatory cytokines lowering erythropoietin production. J Interferon Cytokine Res 1998;18:555-559.

33 Wagner M, Alam A, Zimmermann J, Rauh K, Koljaja-Batzner A, Raff U, Wanner C, Schramm L: Endogenous erythropoietin and the association with inflammation and mortality in diabetic chronic kidney disease. Clin J Am Soc Nephrol 2011;6:1573-1579.

34 Babitt JL, Lin HY: Molecular mechanisms of hepcidin regulation: implications for the anemia of CKD. Am J Kidney Dis 2010;55: 726-741.

35 Crews DC, Sozio SM, Liu Y, Coresh J, Powe NR: Inflammation and the paradox of racial differences in dialysis survival. J Am Soc Nephrol 2011;22:2279-2286.

36 Wing MR, Yang W, Teal V, Navaneethan S, Tao K, Ojo A, Guzman NN, Reilly M, Wolman M, Rosas SE, Cuevas M, Fischer M, Lustigova E, Master SR, Xie D, Appleby D,
Joffe M, Kusek J, Feldman HI, Raj DS: Race modifies the association between adiposity and inflammation in patients with chronic kidney disease: findings from the chronic renal insufficiency cohort study. Obesity (Silver Spring) 2014;22:1359-1366.

37 Okada R, Wakai K, Naito M, Morita E, Kawai S, Hamajima N, Hara M, Takashima N, Suzuki S, Takezaki T, Ohnaka K, Arisawa K, Hirohata H, Matsuo K, Mikami H, Kubo M, Tanaka H: Pro-/anti-inflammatory cytokine gene polymorphisms and chronic kidney disease: a crosssectional study. BMC Nephrol 2012;13:2.

38 Girndt M, Kaul H, Sester U, Ulrich C, Sester $\mathrm{M}$, Georg T, Kohler H: Anti-inflammatory interleukin-10 genotype protects dialysis patients from cardiovascular events. Kidney Int 2002;62:949-955.

-39 Holtzman S, Abbey SE, Chan C, Bargman JM, Stewart DE: A genetic predisposition to produce low levels of IL-10 is related to depressive symptoms: a pilot study of patients with end stage renal disease. Psychosomatics 2012; 53:155-161.

40 Rosengren BI, Sagstad SJ, Karlsen TV, Wiig $\mathrm{H}$ : Isolation of interstitial fluid and demonstration of local proinflammatory cytokine production and increased absorptive gradient in chronic peritoneal dialysis. Am J Physiol Renal Physiol 2013;304:F198-F206.

41 Kim HJ, Vaziri ND: Contribution of impaired Nrf2-Keap1 pathway to oxidative stress and inflammation in chronic renal failure. Am J Physiol Renal Physiol 2010;298:F662-F671.

42 Aveles PR, Criminacio CR, Goncalves S, Bignelli AT, Claro LM, Siqueira SS, Nakao LS, Pecoits-Filho R: Association between biomarkers of carbonyl stress with increased systemic inflammatory response in different stages of chronic kidney disease and after renal transplantation. Nephron Clin Pract 2010; 116:c294-c299.

43 Prats M, Font R, Garcia C, Munoz-Cortes M, Cabre C, Jariod M, Romeu M, Giralt M, Martinez-Vea A: Oxidative stress markers in predicting response to treatment with ferric carboxymaltose in nondialysis chronic kidney disease patients. Clin Nephrol 2014;81:419-426.

44 Ori Y, Bergman M, Bessler H, Zingerman B, Levy-Drummer RS, Gafter U, Salman H: Cytokine secretion and markers of inflammation in relation to acidosis among chronic hemodialysis patients. Blood Purif 2013;35:181-186.

$\checkmark 45$ Nassar GM: Preventing and treating inflammation: role of dialysis access management. Semin Dial 2013;26:28-30.

46 Ruospo M, Palmer SC, Craig JC, Gentile G, Johnson DW, Ford PJ, Tonelli M, Petruzzi M, De Benedittis M, Strippoli GF: Prevalence and severity of oral disease in adults with chronic kidney disease: a systematic review of observational studies. Nephrol Dial Transplant 2014;29:364-375.

47 Buhlin K, Barany P, Heimburger O, Stenvinkel P, Gustafsson A: Oral health and pro-inflammatory status in end-stage renal disease patients. Oral Health Prev Dent 2007;5:235-244. 
-48 Kshirsagar AV, Craig RG, Moss KL, Beck JD, Offenbacher S, Kotanko P, Klemmer PJ, Yoshino M, Levin NW, Yip JK, Almas K, Lupovici EM, Usvyat LA, Falk RJ: Periodontal disease adversely affects the survival of patients with end-stage renal disease. Kidney Int 2009, 75:746-751.

49 Anders HJ, Andersen K, Stecher B: The intestinal microbiota, a leaky gut, and abnormal immunity in kidney disease. Kidney Int 2013 83:1010-1016.

-50 Shi K, Wang F, Jiang H, Liu H, Wei M, Wang Z, Xie L: Gut bacterial translocation may aggravate microinflammation in hemodialysis patients. Dig Dis Sci 2014;59:2109-2117.

51 Natarajan R, Pechenyak B, Vyas U, Ranganathan P, Weinberg A, Liang P, Mallappallil MC, Norin AJ, Friedman EA, Saggi SJ: Randomized controlled trial of strain-specific probiotic formulation (Renadyl) in dialysis patients. Biomed Res Int 2014;2014:568571.

- 52 Rossi M, Campbell KL, Johnson DW, Stanton T, Vesey DA, Coombes JS, Weston KS, Hawley CM, McWhinney BC, Ungerer JP, Isbel N: Protein-bound uremic toxins, inflammation and oxidative stress: a cross-sectional study in stage 3-4 chronic kidney disease. Arch Med Res 2014;45:309-317.

53 Icardi A, Paoletti E, De Nicola L, Mazzaferro S, Russo R, Cozzolino M: Renal anaemia and EPO hyporesponsiveness associated with vitamin D deficiency: the potential role of inflammation. Nephrol Dial Transplant 2013; 28:1672-1679.

54 Sterling KA, Eftekhari P, Girndt M, Kimmel PL, Raj DS: The immunoregulatory function of vitamin D: implications in chronic kidney disease. Nat Rev Nephrol 2012;8: 403-412.

-55 Roubicek T, Bartlova M, Krajickova J, Haluzikova D, Mraz M, Lacinova Z, Kudla M, Teplan V, Haluzik M: Increased production of proinflammatory cytokines in adipose tissue of patients with end-stage renal disease. Nutrition 2009;25:762-768.

-56 Kerr JD, Holden RM, Morton AR, Nolan RL, Hopman WM, Pruss CM, Garland JS: Associations of epicardial fat with coronary calcification, insulin resistance, inflammation, and fibroblast growth factor-23 in stage 3-5 chronic kidney disease. BMC Nephrol 2013;14:26.

57 Nehus E, Furth S, Warady B, Mitsnefes M: Correlates of leptin in children with chronic kidney disease. J Pediatr 2014; 165:825829.

58 Martinez Cantarin MP, Keith SW, Waldman SA, Falkner B: Adiponectin receptor and adiponectin signaling in human tissue among $\mathrm{pa}$ tients with end-stage renal disease. Nephrol Dial Transplant 2014;pii:gfu249, Epub ahead of print.

59 Friedrich B, Alexander D, Janessa A, Haring HU, Lang F, Risler T: Acute effects of hemodialysis on cytokine transcription profiles: evidence for C-reactive protein-dependency of mediator induction. Kidney Int 2006;70: 2124-2130.
60 Santoro A, Mancini E: Is hemodiafiltration the technical solution to chronic inflammation affecting hemodialysis patients? Kidney Int 2014;86:235-237.

61 Panichi V, Paoletti S, Consani C: Inflammatory pattern in hemodiafiltration. Contrib Nephrol 2008;161:185-190.

62 Carrero JJ, Yilmaz MI, Lindholm B, Stenvinkel P: Cytokine dysregulation in chronic kidney disease: how can we treat it? Blood Purif 2008;26:291-299.

63 Kalantar-Zadeh K, Cano NJ, Budde K, Chazot C, Kovesdy CP, Mak RH, Mehrotra R, Raj DS, Sehgal AR, Stenvinkel P, Ikizler TA: Diets and enteral supplements for improving outcomes in chronic kidney disease. Nat Rev Nephrol 2011;7:369-384.

64 Ikizler TA, Cano NJ, Franch H, Fouque D, Himmelfarb J, Kalantar-Zadeh K, Kuhlmann MK, Stenvinkel P, TerWee P, Teta D, Wang AY, Wanner C: Prevention and treatment of protein energy wasting in chronic kidney disease patients: a consensus statement by the International Society of Renal Nutrition and Metabolism. Kidney Int 2013; 84:1096-1107.

65 Eustace JA, Coresh J, Kutchey C, Te PL, Gimenez LF, Scheel PJ, Walser M: Randomized double-blind trial of oral essential amino acids for dialysis-associated hypoalbuminemia. Kidney Int 2000;57:2527-2538.

66 Hsu SP, Wu MS, Yang CC, Huang KC, Liou SY, Hsu SM, Chien CT: Chronic green tea extract supplementation reduces hemodialysisenhanced production of hydrogen peroxide and hypochlorous acid, atherosclerotic factors, and proinflammatory cytokines. Am J Clin Nutr 2007;86:1539-1547.

67 Vertolli U, Davis PA, Maso LD, Maiolino G, Naso A, Plebani M, Calò LA: Daily green tea extract supplementation reduces prothrombotic and inflammatory states in dialysis patients. J Funct Foods 2013;5:1366-1371.

68 Fanti P, Asmis R, Stephenson TJ, Sawaya BP, Franke AA: Positive effect of dietary soy in ESRD patients with systemic inflammation correlation between blood levels of the soy isoflavones and the acute-phase reactants. Nephrol Dial Transplant 2006;21:2239-2246.

69 Guebre-Egziabher F, Debard C, Drai J, Denis L, Pesenti S, Bienvenu J, Vidal H, Laville M, Fouque D: Differential dose effect of fish oil on inflammation and adipose tissue gene expression in chronic kidney disease patients. Nutrition 2013;29:730-736.

70 Himmelfarb J, Phinney S, Ikizler TA, Kane J, McMonagle E, Miller G: Gamma-tocopherol and docosahexaenoic acid decrease inflammation in dialysis patients. J Ren Nutr 2007; 17:296-304

71 Li K, Huang T, Zheng J, Wu K, Li D: Effect of marine-derived $n-3$ polyunsaturated fatty acids on C-reactive protein, interleukin 6 and tumor necrosis factor alpha: a meta-analysis. PLoS One 2014;9:e88103.

72 Shema-Didi L, Sela S, Ore L, Shapiro G, Geron R, Moshe G, Kristal B: One year of pomegran- ate juice intake decreases oxidative stress, inflammation, and incidence of infections in hemodialysis patients: a randomized placebocontrolled trial. Free Radic Biol Med 2012;53: 297-304

73 Shema-Didi L, Kristal B, Ore L, Shapiro G, Geron R, Sela S: Pomegranate juice intake attenuates the increase in oxidative stress induced by intravenous iron during hemodialysis. Nutr Res 2013;33:442-446.

74 Miraghajani MS, Esmaillzadeh A, Najafabadi MM, Mirlohi M, Azadbakht L: Soy milk consumption, inflammation, coagulation, and oxidative stress among type 2 diabetic patients with nephropathy. Diabetes Care 2012; 35:1981-1985

75 Krishnamurthy VM, Wei G, Baird BC Murtaugh M, Chonchol MB, Raphael KL, Greene T, Beddhu S: High dietary fiber intake is associated with decreased inflammation and all-cause mortality in patients with chronic kidney disease. Kidney Int 2012;81: 300-306.

76 Di Cerbo A, Pezzuto F, Palmieri L, Rottigni V, Iannitti T, Palmieri B: Clinical and experimental use of probiotic formulations for management of end-stage renal disease: an update. Int Urol Nephrol 2013;45:1569-1576.

77 Ramezani A, Raj DS: The gut microbiome, kidney disease, and targeted interventions. J Am Soc Nephrol 2014;25:657-670.

78 Wei $\mathrm{M}$, Wang $\mathrm{Z}$, Liu $\mathrm{H}$, Jiang $\mathrm{H}$, Wang $\mathrm{M}$, Liang S, Shi K, Feng J: Probiotic Bifidobacterium animalis subsp. lactis $\mathrm{Bi}-07$ alleviates bacterial translocation and ameliorates microinflammation in experimental uraemia. Nephrology (Carlton) 2014;19:500-506.

-79 Stubbs JR, Idiculla A, Slusser J, Menard R, Quarles LD: Cholecalciferol supplementation alters calcitriol-responsive monocyte proteins and decreases inflammatory cytokines in ESRD. J Am Soc Nephrol 2010;21:353-361.

- 80 Hansen D, Rasmussen K, Rasmussen LM, Bruunsgaard $\mathrm{H}$, Brandi L: The influence of vitamin $\mathrm{D}$ analogs on calcification modulators, N-terminal pro-B-type natriuretic peptide and inflammatory markers in hemodialysis patients: a randomized crossover study. BMC Nephrol 2014;15:130.

-81 Lohr J, Grotevendt A, Nauck M, Volzke H Wallaschofski H, Friedrich N: Relation of insulin-like growth factor-I and IGF binding protein 3 with markers of inflammation: results of a population-based study. Clin Endocrinol (Oxf) 2014;80:148-154.

82 Carney EF: Chronic kidney disease. Walking reduces inflammation in predialysis CKD. Nat Rev Nephrol 2014;10:300.

83 Viana JL, Kosmadakis GC, Watson EL, Bevington A, Feehally J, Bishop NC, Smith AC: Evidence for anti-inflammatory effects of exercise in CKD. J Am Soc Nephrol 2014;25: 2121-2130.

84 Gould DW, Graham-Brown MP, Watson EL, Viana JL, Smith AC: Physiological benefits of exercise in pre-dialysis chronic kidney disease. Nephrology (Carlton) 2014;19:519-527. 
85 Deng J, Wu Q, Liao Y, Huo D, Yang Z: Effect of statins on chronic inflammation and nutrition status in renal dialysis patients: a systematic review and meta-analysis. Nephrology (Carlton) 2012;17:545-551.

86 de Vinuesa SG, Goicoechea M, Kanter J, Puerta M, Cachofeiro V, Lahera V, Gomez-Campdera F, Luno J: Insulin resistance, inflammatory biomarkers, and adipokines in patients with chronic kidney disease: effects of angiotensin II blockade. J Am Soc Nephrol 2006; 17:S206-S212.

87 Oparil S: Low sodium intake - cardiovascular health benefit or risk? N Engl J Med 2014;371: 677-679.

-88 Campbell KL, Johnson DW, Bauer JD, Hawley CM, Isbel NM, Stowasser M, Whitehead JP, Dimeski G, McMahon E: A randomized trial of sodium-restriction on kidney function, fluid volume and adipokines in CKD patients. BMC Nephrol 2014;15:57.
89 Yang SK, Xiao L, Xu B, Xu XX, Liu FY, Sun L: Effects of vitamin E-coated dialyzer on oxidative stress and inflammation status in hemodialysis patients: a systematic review and meta-analysis. Ren Fail 2014;36:722-731.

90 Hung AM, Ellis CD, Shintani A, Booker C, Ikizler TA: IL-1beta receptor antagonist reduces inflammation in hemodialysis patients. J Am Soc Nephrol 2011;22:437-442.

$\$ 91$ Hung AM, Limkunakul C, Placido JS, Siew ED, Ellis CD, Shintani A, Ikizler TA: Administration of IL-1ra improves adiponectin levels in chronic hemodialysis patients. J Nephrol 2014, Epub ahead of print.

92 Susantitaphong P, Riella C, Jaber BL: Effect of ultrapure dialysate on markers of inflammation, oxidative stress, nutrition and anemia parameters: a meta-analysis. Nephrol Dial Transplant 2013;28:438-446.

93 Ayus JC, Mizani MR, Achinger SG, Thadhani R, Go AS, Lee S: Effects of short daily versus conventional hemodialysis on left ventricular hypertrophy and inflammatory markers: a prospective, controlled study. J Am Soc Nephrol 2005;16:2778-2788.
94 Susantitaphong P, Koulouridis I, Balk EM, Madias NE, Jaber BL: Effect of frequent or extended hemodialysis on cardiovascular parameters: a meta-analysis. Am J Kidney Dis 2012;59:689-699.

95 den Hoedt CH, Bots ML, Grooteman MP, van der Weerd NC, Mazairac AH, Penne EL, Levesque R, ter Wee PM, Nube MJ, Blankestijn PJ, van den Dorpel MA: Online hemodiafiltration reduces systemic inflammation compared to low-flux hemodialysis. Kidney Int 2014;86:423-432.

96 Panichi V, Rizza GM, Paoletti S, Bigazzi R, Aloisi M, Barsotti G, Rindi P, Donati G, Antonelli A, Panicucci E, Tripepi G, Tetta C, Palla R: Chronic inflammation and mortality in haemodialysis: effect of different renal replacement therapies. Results from the RISCAVID study. Nephrol Dial Transplant 2008;23:2337-2343. 